\title{
Bone Marrow-Derived Mesenchymal Stem Cells Differentiate to Hepatic Myofibroblasts by Transforming Growth Factor- $\beta 1$ via Sphingosine Kinase/Sphingosine 1-Phosphate (S1P)/S1P Receptor Axis
}

Le Yang, Na Chang, Xin Liu, Zhen Han, Tieping Zhu, Changyong Li, Lin Yang, and Liying Li

From the Department of Cell Biology, Municipal Laboratory for Liver Protection and Regulation of Regeneration, Capital Medical University, Beijing, China

Sphingosine kinase ( $\mathrm{SphK}$ ) is involved in numerous biological processes, including cell growth, proliferation, and differentiation. However, whether SphK participates in the differentiation of bone marrowderived mesenchymal stem cells (BMSCs) to myofibroblasts has been unknown. In a carbon tetrachloride-treated mouse model, SphK1 was expressed in BMSCs in damaged liver. Furthermore, mRNA expression of both SphK1 and transforming growth factor $\beta 1$ (TGF- $\beta 1$ ) was significantly increased after liver injury, with a positive correlation between them. The SphK inhibitor SKI significantly blocked BMSC differentiation to myofibroblasts during liver injury (the proportion of BMSC-derived myofibroblasts decreased markedly, compared with no SKI treatment) and attenuated the extent of liver fibrosis. Using primary mouse BMSCs, we demonstrated that TGF- $\beta 1$ induced BMSC differentiation to myofibroblasts, accompanied by the up-regulation of SphK1 and modulation of sphingosine 1-phosphate (S1P) receptor (S1PR) expression. Notably, pharmacological or siRNA-mediated inhibition of SphK1 abrogated the prodifferentiating effect of TGF- $\beta 1$. Moreover, using either S1PR subtype-specific antagonists or specific siRNAs, we found that the prodifferentiating effect of TGF- $\beta 1$ was mediated by $\mathrm{S1PR}_{1}$ and $S 1 \mathrm{PR}_{3}$. These data suggest that SphK1 activation by TGF- $\beta 1$ leads to differentiation of BMSCs to myofibroblasts mediated by S1PR and $\mathrm{S1PR}_{3}$ up-regulation, thus providing new information on the mechanisms by which TGF- $\beta 1$ gives rise to fibrosis and opening new perspectives for pharmacological treatment of liver fibrosis. (Am J Pathol 2012, 181: 85-97; bttp://dx.doi.org/10.1016/j.ajpath.2012.03.014)

Mesenchymal stem cells (MSCs) are a heterogeneous population of cells with the potential for multilineage differentiation. They have been identified and isolated from various tissues, including blood, adipose tissue, trabecular bone, muscle, and dermis. ${ }^{1}$ Under appropriate culture conditions, bone marrow-derived MSCs (BMSCs) are capable of differentiating to a variety of mesenchymal tissues, including bone, cartilage, muscle, ligament, tendon, adipose tissue, and stroma. ${ }^{2,3}$ Their multipotency, easy isolation, and ready availability make MSCs particularly suited for tissue engineering and clinical applications. Thus, it is desirable to identify at the molecular level the regulatory mechanisms underlying the differentiation of MSCs.

Myofibroblasts play a central role in the pathogenesis of liver fibrosis. De novo formation of differentiated myofibroblasts is thought to be primarily responsible for excessive extracellular matrix production; thus, elucidating the mechanisms of myofibroblast activation seems indispensable for designing rational therapeutic strategies to inhibit the fibrogenic process the leads to cirrhosis. ${ }^{4,5} \mathrm{~A}$ high proportion of myofibroblasts in the fibrotic liver are of BMSC origin. ${ }^{6-8}$ In a previous study, we demonstrated

Supported by grants from the National Basic Research Program (2008CB517401), the National Natural and Science Foundation of China (81030009, 30971348, 81170407), the Natural Science Foundation of Beijing (7102016), the Funding Project for Academic Human Resources Development in Institutions of Beijing Municipality (PHR201006109), and the Beijing Municipal Commission of Education (YB20101002501).

Accepted for publication March 8, 2012.

Supplemental material for this article can be found on http://ajp. amjpathol.org or at $h t t p: / / d x . d o i . o r g / 10.1016 / j$. ajpath.2012.03.014.

Address reprint requests to Liying Li, Ph.D., No. 10 Xitoutiao, You An Men, Beijing 100069, China. E-mail: liliying@ccmu.edu.cn. 
that BMSCs can migrate to the damaged liver, mediated by endogenous sphingosine 1-phosphate (S1P), which can produce a concentration gradient between liver and bone marrow after liver injury, and that BMSCs differentiate to myofibroblast-like cells expressing $\alpha$-smooth muscle actin $(\alpha-S M A)$ in mouse fibrotic liver. ${ }^{9}$ However, which factor mediates differentiation of BMSCs to myofibroblasts and the molecular mechanisms governing this process are not fully understood.

Sphingosine kinase (SphK) catalyzes the phosphorylation of sphingosine to generate the bioactive lipid S1P. ${ }^{10}$ The two distinct isoforms of mammalian SphK (SphK1 and SphK2) differ in sequence, catalytic properties, localization, and function. ${ }^{11}$ SphK 1 is activated by various factors, including ganglioside GM1 (GM1), Gprotein coupled receptors, small GTPases, tyrosine kinase receptors, proinflammatory cytokines, immunoglobulin receptors, and calcium and protein kinase activators, and is involved in numerous biological processes, including cell growth, proliferation, differentiation, apoptosis, motility, and cytoskeletal rearrangement. ${ }^{12-15}$ SphK1 activation translocates from the cytosol to the plasma membrane, leading to S1P formation, which then activates a set of five G-protein-coupled receptors referred to as S1P receptor (S1PR) types 1 to $5\left(\mathrm{~S}_{\mathrm{PR}} \mathrm{1}_{-5}\right)$, leading to regulation of numerous downstream signaling components. ${ }^{16}$ It is becoming increasingly clear that the expression pattern of S1PRs is critical for the final effect elicited by the bioactive lipid in some cell types, given that individual receptor subtypes are coupled to different signaling cascades and are consequently implicated in the regulation of a variety of biological responses. ${ }^{17,18}$

Transforming growth factor- $\beta 1$ (TGF- $\beta 1$ ) is a member of a large family of growth factors involved in numerous biological processes, including cell proliferation, differentiation, embryonic development, carcinogenesis, immune function, inflammation, and wound healing. ${ }^{19-22}$ Some of the effects elicited by TGF- $\beta 1$ are transmitted by the pathway initiated by enhancement of SphK. The SphK/S1P/S1PR pathway is critically implicated in the mechanism by which TGF- $\beta 1$ elicits invasive behavior of esophageal cancer cells, ${ }^{23}$ antiapoptotic action in mesoangioblasts, ${ }^{24}$ and prodifferentiating effect in various types of fibroblasts ${ }^{25-27}$ and myoblasts. ${ }^{28}$ In particular, up-regulation of SphK1 has been found to be critical for TGF- $\beta 1$-induced transcriptional regulation of the tissue inhibitor of metalloproteinases 1 (TIMP-1), which inhibits degradation of extracellular matrix in fibroblasts. ${ }^{25}$ Moreover, recent reports have shown that SphK1 and S1PRs play a role in TGF- $\beta 1$-dependent extracellular matrix remodeling and myofibroblast differentiation of lung fibroblasts and myoblasts and in collagen production by cardiac fibroblasts. ${ }^{26-28}$ The well-established prodifferentiating effect of TGF- $\beta 1$, together with the emerging role of the SphK/S1P/ S1PR axis as the TGF- $\beta 1$-regulated signaling pathway, spurred us to investigate whether TGF- $\beta 1$ could induce differentiation of BMSCs to myofibroblasts and whether SphK1 and S1PRs participate in its biological action.

With the present study, we demonstrate for the first time that TGF- $\beta 1$ induces differentiation of BMSCs to myofibroblasts via up-regulation of SphK1 and modifica- tion of S1PR expression. Importantly, S1PR 1 and $\mathrm{S}_{1} \mathrm{PR}_{3}$, which are up-regulated on TGF- $\beta 1$ challenge, seem to be critically implicated in the differentiation of BMSCs to myofibroblasts. In vivo administration of SphK inhibitor significantly blocked differentiation of BMSCs to myofibroblasts during liver injury, and thus attenuated the extent of liver fibrosis. These results represent the first experimental evidence that induction of the SphK/S1P/ S1PR axis is exploited by TGF- $\beta 1$ to induce BMSC differentiation. These results may open new perspectives for pharmacological treatment of liver fibrosis.

\section{Materials and Methods}

\section{Chemicals and Reagents}

Antibodies against $\alpha$-SMA and SphK1 were from SigmaAldrich (St. Louis, MO) and ECM Biosciences (Versailles, KY), respectively. Anti-CD105 and anti-CD166 antibodies used for flow cytometry analysis were from $A b D$ Serotec (Kidlington, UK) and BD Biosciences (San Jose, CA), respectively. TGF- $\beta 1$ was from PeproTech (London, UK), and GM1 was from Sigma-Aldrich. The sphingosine kinase inhibitor SKI [2-(p-hydroxyanilino)-4-(p-chlorophenyl)thiazole] and $N, N$-dimethylsphingosine (DMS) were from Calbiochem (Bad Soden, Germany) and Biomol (Hamburg, Germany), respectively. The specific S1PR 1 $\mathrm{S}_{1 P R_{3}}$ antagonist VPC23019 and the specific S1PR 1 antagonist W146 were from Avanti Polar Lipids (Alabaster, $\mathrm{AL}$ ). The specific $\mathrm{S}_{\mathrm{PR}}$ antagonist JTE-013 and the $\mathrm{S}_{1 \mathrm{PR}}$ agonist SEW2871 were from Cayman Chemical (Ann Arbor, MI). PCR reagents were from Applied Biosystems (Life Technologies, Foster City, CA). Alkaline phosphatase type VII-T, o-phthalaldehyde, and other common reagents were from Sigma-Aldrich.

\section{Isolation of Whole Bone Marrow Cells and BMSCs}

ICR mice aged 3 weeks (Laboratory Animal Center, Capital Medical University) were sacrificed by cervical dislocation. Whole bone marrow cells were extracted from the tibias and femurs of mice by flushing with Gibco culture medium (Life Technologies, Grand Island, NY) using a 25 -gauge needle. The cells were then passed through 70-mm nylon mesh and were washed three times with PBS containing $2 \%$ fetal bovine serum (Biochrom, Berlin, Germany). BMSCs were isolated from bone marrow of enhanced green fluorescent protein (EGFP) transgenic ICR mice or wild-type mice, and were cultured as described previously. ${ }^{9}$ Characterization of BMSCs was performed by flow cytometry analysis. ${ }^{9}$ All animal experiments were performed according to guidelines of the Ethics Committee of Capital Medical University.

\section{Mouse Models}

ICR mice aged 6 weeks received intraperitoneal injections of $1 \mu \mathrm{L} / \mathrm{g}$ body weight of a carbon tetrachloride/olive oil $\left(\mathrm{CCl}_{4} / \mathrm{OO}\right)$ mixture, $1: 9 \mathrm{v} / \mathrm{v}$, twice per week. The mice were sacrificed at 3 days or at 2, 4, 6, or 8 weeks of $\mathrm{CCl}_{4}$ 
treatment ( $n=7$ per group), always on the day after the last injection. Liver tissue was collected for real-time RT-PCR and high-performance liquid chromatography (HPLC) analysis.

Another group of mice received lethal irradiation (8 Gy), and then immediately received transplantation by a tail-vein injection of $1.2 \times 10^{6}$ enriched EGFP-positive BMSCs and $1.08 \times 10^{7}$ EGFP-negative whole bone marrow cells. Four weeks later, mice received intraperitoneal injections of $\mathrm{CCl}_{4}$ twice per week for 4 weeks. SKI $(10 \mathrm{mg} / \mathrm{kg}$ body weight) or saline was administered the day before $\mathrm{CCl}_{4}$ or $\mathrm{OO}$ treatment ( $n=7$ per group). Liver tissue was collected for real-time RT-PCR, for H\&E and Sirius Red staining, and for immunofluorescence analysis.

\section{Immunofluorescence}

Liver samples were fixed in $4 \%$ paraformaldehyde and embedded in Tissue Tek optimal cutting temperature compound (Sakura Finetek USA, Torrance, CA). Frozen sections ( $7 \mu \mathrm{m}$ thick) were used for immunofluorescence staining. Sections were blocked with $2 \%$ bovine serum albumin in PBS for 1 hour and then incubated with antiSphK1 polyclonal antibody (1:100) diluted in PBS. Cy3conjugated AffiniPure goat anti-rabbit IgG antibody (1: 500) was used as a secondary antibody (Jackson ImmunoResearch Laboratories, West Grove, PA). The sections were covered with Vectashield mounting medium (Vector Laboratories, Burlingame, CA) containing DAPI and were observed under a confocal microscope (Leica TCS SP5 with LAS AF version 2.5 software; Leica Microsystems, Wetzlar, Germany). For negative controls, sections were processed the same way, except that incubation with the primary antibody was omitted.

Immunofluorescent detection of $\alpha$-SMA in liver tissue was performed using a Vector M.O.M. (mouse-on-mouse) immunodetection kit (Vector Laboratories) and a 1:1000 dilution of a monoclonal antibody to $\alpha$-SMA. The proportion of BMSC-derived myofibroblasts was calculated as the number of both EGFP-positive and $\alpha$-SMA-positive cells divided by number of $\alpha$-SMA-positive cells, using Image-Pro Plus version 6.0 software (Media Cybernetics, Silver Spring, MD).

Cultured BMSCs with or without treatments were fixed in $4 \%$ paraformaldehyde in PBS for 30 minutes. Then cells were washed twice with PBS, permeabilized in $0.5 \%$ Triton X-100 in PBS for 15 minutes, blocked with 2\% BSA for 1 hour, and then incubated with anti- $\alpha$-SMA monoclonal antibody (1: 2000), followed by secondary antibody conjugated with Cy3 (1:1000; Jackson ImmunoResearch Laboratories).

\section{Real-Time RT-PCR}

Total RNA was extracted from frozen liver specimens or cultured BMSCs with or without treatments, using an RNeasy kit (Qiagen, Hilden, Germany). Real-time RTPCR was performed with an ABI Prism 7300 sequence-detecting system (Life Technologies, Foster City, CA), as described previously. ${ }^{29}$ Primers (MWG Biotech, Ebersberg, Germany) used for real-time RT-PCR were as follows: 18S rRNA, sense, 5'-GTAACCCGTTGAACCCCATT-3', and antisense, 5'-CCATCCAATCGGTAGTAGCG-3'; $\alpha$-SMA, sense, 5'-ATGCTCCCAGGGCTGTTा-3', and anti-sense, 5'-TTC-
CAACCATTACTCCCTGATGT-3'; SphK1, sense, 5'-TGTCACCCATGAACCTGCTGTCCCTGCACA-3' ${ }^{\prime}$, and anti-sense, 5'-AGAAGGCACTGGCTCCAGAGGAACAAG-3'; SphK2, sense, 5'-ACAGAACCATGCCCGTGAG-3', and anti-sense, 5'-AGGTCAACACCGACAACCTG-3'; procollagen $\alpha 1(\mathrm{I})$ [Col $\alpha 1(\mathrm{I})]$, sense, 5'-AGGGCGAGTGCTGTGCTT T-3', and anti-sense, 5'-CCCTCGACTCCTACATCTTCTGA-3'; procollagen $\alpha 1$ (III) [Col $\alpha 1\left(\right.$ III)], sense, $5^{\prime}$-TGAAACCCCAGCAAAACAAAA-3', and anti-sense, 5'-TCACTTGCACTGGTTGATAAGATTAA-3'; S1PR , sense, 5'-ACTTGCGAGTGAGCTG-3', and anti-sense, 5'-AGTGAGCCTTCAGTTACAGC-3'; S1PR ${ }_{2}$, sense, 5'-TTCTGGAGGGTAACACAGTGGT-3', and antisense, 5'-ACACCCTITGTATCAAGTGGCA-3'; S1PR $_{3}$, sense, 5'-TGGTGTGCGGCTGTCTAGTCAA-3', and anti-sense, 5'CACAGCAAGCAGACCTCCAGA- $3^{\prime}$; and TGF- $\beta 1$, sense, $5^{\prime}$ TGCGCTTGCAGAGATTAAAA-3', and anti-sense, 5'-TCACTGGAGTTGTACGGCAG-3'.

\section{Quantitative Analysis of Liver Fibrosis}

Liver tissues were fixed in PBS containing 4\% paraformaldehyde for 24 hours and then were embedded in paraffin. Sections (6 $\mu \mathrm{m}$ thick) were stained with Sirius Red for collagen visualization and with H\&E for liver histology, as described previously. ${ }^{30}$ The fibrotic area was assessed by means of computer-assisted image analysis with Leica Qwin V3 software. The expressed percentage of fibrotic or inflammatory area was calculated based on the mean value of 15 randomly selected areas per sample.

\section{Western Blot Analysis}

Western blot analysis of $\alpha$-SMA and SphK 1 was performed with $20 \mu \mathrm{g}$ of protein extract, obtained as described previously, ${ }^{31}$ using mouse monoclonal antibody and rabbit polyclonal antibody to $\alpha$-SMA $(1: 1000)$ and SphK1 (1:1000), respectively. Peroxidase-conjugated goat anti-mouse or goat anti-rabbit IgG antibody (1:5000; Jackson ImmunoResearch Laboratories) was used as a secondary antibody. Protein expression was visualized by using an enhanced chemiluminescence assay kit according to the manufacturer's instructions (Amersham ECL Plus; GE Healthcare Life Sciences, Arlington Heights, IL). The bands were quantified using GeneSnap and GeneTools software from PerkinElmer (Waltham, $M A$ ), and results were normalized relative to the glyceraldehyde-3-phosphate dehydrogenase (GAPDH) (rabbit monoclonal anti-GAPDH antibody, 1:1000; Sigma-Aldrich) or tubulin (rabbit monoclonal anti-tubulin antibody, 1:1000, Epitomics, Burlingame, CA) expression to correct for variations in protein loading and transfer.

\section{RNA Interference}

The siRNA sequences specifically targeting mouse SphK1, S1PR, $\mathrm{S}_{1} \mathrm{PR}_{2}$, or S1PR 3 were synthesized by Dharmacon: L-040671-00, L-051684-00, L-063765-00, and L-04095900 , respectively (Thermo Scientific, Lafayette, CO). At $40 \%$ to $50 \%$ confluency, BMSCs were prepared in $60-\mathrm{mm}$ dishes. Transient transfection of siRNA (40 nmol/L) was performed by using Invitrogen Lipofectamine RNAiMAX 
(Life Technologies, Carlsbad, CA), as recommended by the manufacturer. Control cells were treated with 40 nmol/L RNAi negative control duplexes (scrambled siRNA). After 48 hours, cells were used to perform the differentiation assay.

\section{Measurement of S1P by HPLC Analysis}

After 24 hours stimulation of TGF- $\beta 1$ or GM1, both BMSCs and their supernatants were collected. Extraction of S1P and sample analysis were performed as described previously. ${ }^{32}$

\section{Statistical Analysis}

Data are expressed as means \pm SEM and were analyzed by Student's $t$-test or analysis of variance when appropriate. $P<0.05$ was considered significant.

\section{Results}

\section{SphK Is Involved in the Differentiation of BMSCs to Myofibroblasts in Mouse Fibrotic Liver}

We first reconstituted bone marrow in the irradiated mice by transplantation of the genetic EGFP-labeled BMSCs. Liver fibrosis was then induced by the administration of $\mathrm{CCl}_{4}$ for 4 weeks, and expression of $\alpha$-SMA, a marker for myofibroblasts, was examined in the damaged liver by immunofluorescence analysis. In OO-treated liver, $\alpha$-SMA was expressed only in the vascular area, and there were only a few, scattered EGFP-positive cells (BMSCs) in the liver. No colocalization was observed between $\alpha$-SMA-positive and EGFP-positive cells (Figure 1A). After $\mathrm{CCl}_{4}$ treatment, however, there was strong immunoreactivity for $\alpha$-SMA in the fibrotic areas, with distribution similar to that of EGFP-positive cells (Figure 1B). Confocal microscopy images showed that these EGFP-positive cells (BMSCs) had a myofibroblast phenotype (Figure 1C). We then determined the proportion of BMSC-derived myofibroblasts and found that a large proportion (69\%) of $\alpha$-SMA-positive cells in the fibrotic areas were also positive for EGFP, suggesting that BMSCs could differentiate to myofibroblasts during liver fibrosis (Figure 1E). We also quantitated the numbers of myofibroblasts of non-bone marrow origin (including hepatic stellate cells); the percentage was only $31 \%$. Given the significant contribution of BMSCs to the myofibroblast lineage, we focused on the myofibroblasts derived from BMSC differentiation.

To prove fully that BMSCs actually leave the bone marrow and then engraft the liver, we used flow cytometry analysis to explore whether the EGFP-positive cells in the blood of chimeric mice were MSCs. We first characterized these EGFP-positive cells and found that more EGFP-positive cells were detected in the blood of chimeric animals treated with $\mathrm{CCl}_{4}$, compared with the OOtreated control (see Supplemental Figure S1A at $h$ ttp:// ajp.amjpathol.org). Moreover, we used the typical MSC marker proteins, CD166 and CD105, to confirm the phenotype of MSCs in mice treated with $\mathrm{OO}$ or $\mathrm{CCl}_{4}$. Some of the EGFP-positive cells circulating in the blood of chimeric animals were also positive for CD166 (see Supplemental Figure S1B at http://ajp.amjpathol.org) or CD105 (see Supplemental Figure S1C at http://ajp.amjpathol. org). These results suggest that, after liver injury, these MSCs actually leave the bone marrow, enter the circulation, and then traffic to the liver (see Supplemental Figure S1 at $h$ ttp://ajp.amjpathol.org).

SphK is reported to play a pivotal role in the differentiation of many types of cells. ${ }^{25-28}$ To investigate whether SphK/S1P/S1PR signaling is involved in BMSC differentiation, we first examined the mRNA expression of SphK1 in $\mathrm{CCl}_{4}$-induced liver fibrosis models. SphK1 mRNA level increased drastically from 3 days after $\mathrm{CCl}_{4}$ treatment, and continued to increase in a way correlated with the progression of liver fibrosis, with a maximal increase (26.5-fold) at 56 days after $\mathrm{CCl}_{4}$ treatment (Figure 2A). Correspondingly, the production of S1P on SphK1 activation was also increased from 3 to 42 days after $\mathrm{CCl}_{4}$ administration (Figure 2B)

Our results demonstrated that BMSCs differentiated to myofibroblasts in mouse liver fibrosis (Figure 1, B and C). To study the molecular mechanism underlying BMSC differentiation, we next examined whether SphK1 is expressed in BMSCs in mouse fibrotic liver by immunofluorescence analysis. SphK1 was expressed primarily in the vascular area (Figure 2D), which is in accord with previous studies. ${ }^{33}$ In addition, the fibrotic liver displayed strong immunoreactivity for SphK1 in the fibrotic septa. EGFP-positive cells (ie, BMSCs) distributed in a pattern similar to that of SphK1 staining along the fibrotic septa. Confocal microscope images showed that significant numbers of EGFP-positive cells in the fibrotic area were also positive for SphK1 (Figure 2E), suggesting that SphK1 was probably involved in BMSC differentiation.

To determine the role of SphK in BMSC differentiation in vivo, we used a pharmacological inhibitor of SphK, SKI, to investigate whether SphK is involved in the differentiation of BMSCs to myofibroblasts in $\mathrm{CCl}_{4}$-induced liver injury. The SKI significantly blocked differentiation of BMSCs to myofibroblasts during liver injury (Figure 1D), because the proportion of BMSC-derived myofibroblasts decreased markedly compared with that in the liver without SKI treatment (from 69\% to 20\%) (Figure 1E).

We then speculated that S1P, the product of SphK1, may be involved in the differentiation of BMSCs to myofibroblasts. After S1P stimulation, we detected mRNA expression of $\alpha$-SMA and of the major components of the extracellular matrix, Col $\alpha 1(\mathrm{I})$ and Col $\alpha 1$ (III), in BMSCs. Unexpectedly, there were no increases in these mRNA levels after S1P stimulation (Figure 2C). This result suggests that S1P does not directly induce differentiation of BMSCs to myofibroblasts.

\section{SphK1 mRNA and Protein Expression Is Up-Regulated by TGF- $\beta 1$ in BMSCs}

TGF- $\beta 1$ has been reported to be the crucial cytokine inducing the transformation of many types of cells to myofibroblasts. ${ }^{26-28}$ In a previous study we showed that 

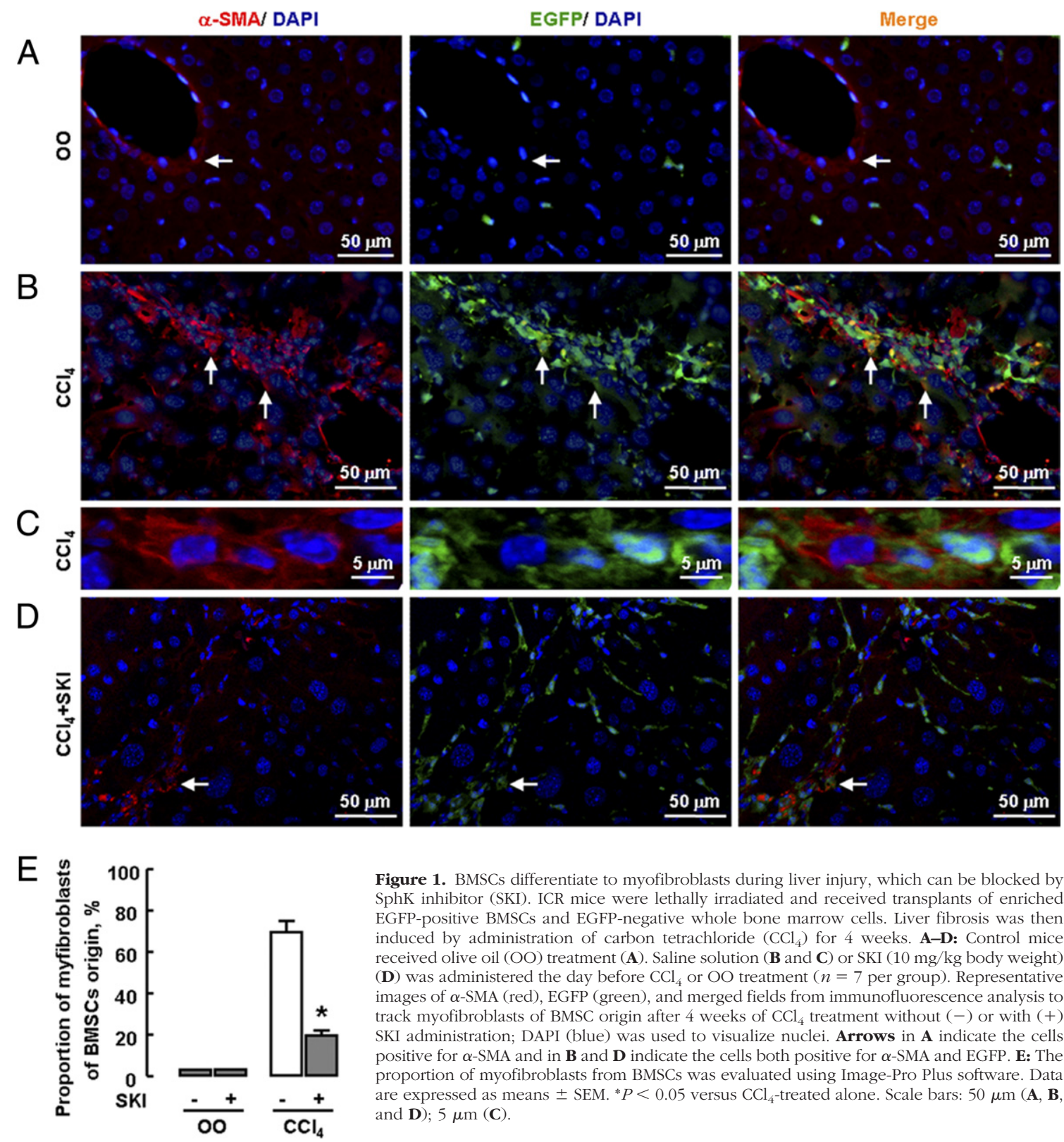

Figure 1. BMSCs differentiate to myofibroblasts during liver injury, which can be blocked by SphK inhibitor (SKI). ICR mice were lethally irradiated and received transplants of enriched EGFP-positive BMSCs and EGFP-negative whole bone marrow cells. Liver fibrosis was then induced by administration of carbon tetrachloride $\left(\mathrm{CCl}_{4}\right)$ for 4 weeks. A-D: Control mice received olive oil (OO) treatment (A). Saline solution (B and C) or SKI (10 mg/kg body weight) (D) was administered the day before $\mathrm{CCl}_{4}$ or OO treatment ( $n=7$ per group). Representative images of $\alpha$-SMA (red), EGFP (green), and merged fields from immunofluorescence analysis to track myofibroblasts of BMSC origin after 4 weeks of $\mathrm{CCl}_{4}$ treatment without $(-)$ or with $(+)$ SKI administration; DAPI (blue) was used to visualize nuclei. Arrows in A indicate the cells positive for $\alpha$-SMA and in $\mathbf{B}$ and $\mathbf{D}$ indicate the cells both positive for $\alpha$-SMA and EGFP. E: The proportion of myofibroblasts from BMSCs was evaluated using Image-Pro Plus software. Data are expressed as means \pm SEM. ${ }^{*} P<0.05$ versus $\mathrm{CCl}_{4}$-treated alone. Scale bars: $50 \mu \mathrm{m}(\mathbf{A}, \mathbf{B}$, and $\mathbf{D}) ; 5 \mu \mathrm{m}(\mathbf{C})$.

TGF- $\beta 1$ induces differentiation of BMSCs to myofibroblasts by stimulating the mRNA expression of $\alpha$-SMA, Col $\alpha 1(\mathrm{I})$, and Col $\alpha 1(\mathrm{III}){ }^{9}$ In the present study, we observed marked up-regulation of TGF- $\beta 1$ mRNA expression in liver tissue after $\mathrm{CCl}_{4}$ treatment (see Supplemental Figure $\mathrm{S} 2$ at $h$ ttp:// ajp.amjpathol.org). To investigate the molecular mechanism underlying BMSC differentiation, we first analyzed the correlation between TGF- $\beta 1$ and SphK1 mRNA in liver. A straight-line fit was obtained in regression analysis between them, with correlation coefficient $r=0.895(P<0.001)$ (Figure 3A), further suggesting that SphK1 highly expressed in fibrotic liver may play a role in the differentiation of BMSCs to myofibroblasts induced by TGF- $\beta 1$.

Reports have indicated that SphK expression can be increased by TGF- $\beta 1$ stimulation in fibroblasts and myoblasts, ${ }^{26-28}$ but whether TGF- $\beta 1$ regulates SphK in BMSCs had not been investigated previously. Real-time
RT-PCR analysis revealed a pronounced increase in SphK1 mRNA expression stimulated by TGF- $\beta 1$ in a dose-dependent manner, with a maximal increase at a concentration of $10 \mathrm{ng} / \mathrm{mL}$ at 24 hours (Figure 3, B and C), in parallel with the maximal up-regulation of $\alpha$-SMA, Col $\alpha 1(\mathrm{I})$, and Col $\alpha 1(\mathrm{III})$ (see Supplemental Figure S3 at $h$ ttp://ajp.amjpathol.org). We next examined the effects of TGF- $\beta 1$ on SphK1 protein expression by Western blot. TGF- $\beta 1$ treatment markedly up-regulated SphK1 protein levels at 24 hours, with a maximal increase at 48 hours (Figure 3D); in controls (0 hour), levels were barely detectable. The elevated levels of SphK1 protein persisted for at least 72 hours. In contrast, SphK2 expression levels were not affected by TGF- $\beta 1$ treatment (data not shown). Together, these data demonstrate that SphK1 mRNA and protein levels are increased by TGF- $\beta 1$ in BMSCs, suggesting that SphK1 might play a key role in the biological effects of TGF- $\beta 1$. 
A

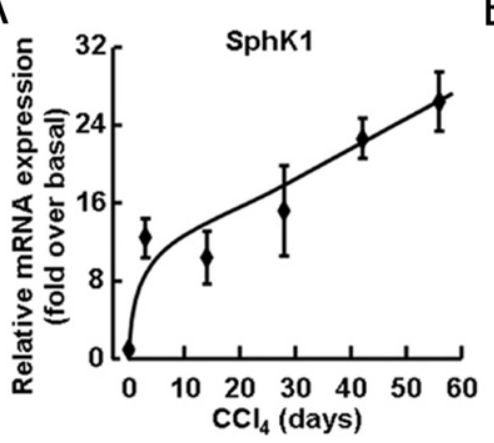

SphK1/ DAPI

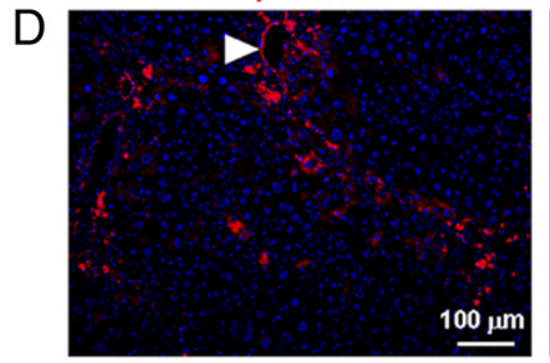

E

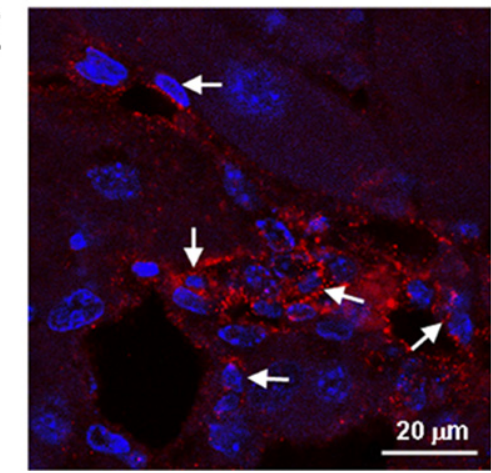

B

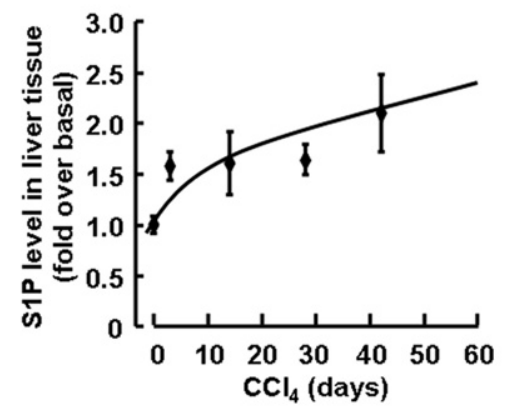

EGFP/ DAPI
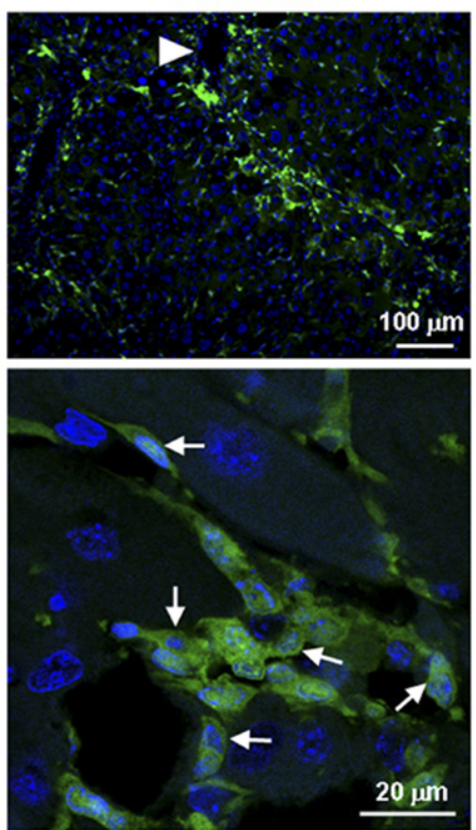

C

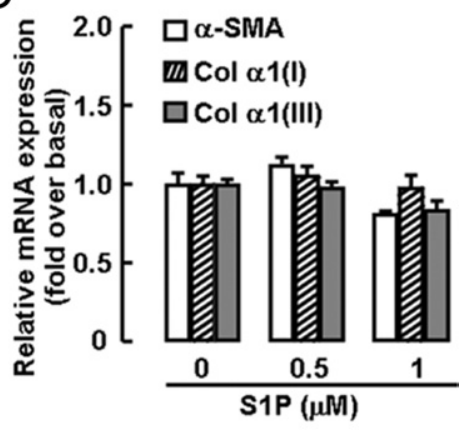

Merge
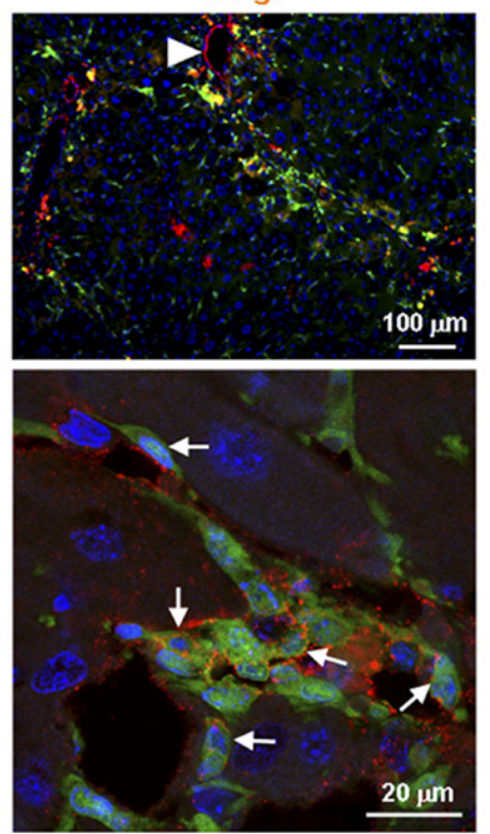

Figure 2. SphK1 is expressed in BMSCs in damaged liver. Total RNA was extracted from liver in mice treated with $\mathrm{CCl}_{4}$ or OO $(n=7$ per group). A: $\mathrm{mRNA}$ expression was quantified using real-time RT-PCR. B: S1P production was analyzed by HPLC. C: mRNA expression of $\alpha$-SMA, Col $\alpha 1$ (I), and Col $\alpha 1(\mathrm{III})$ in confluent serum-starved BMSCs in response to exogenous S1P. D and E: Representative images from immunofluorescence analysis to track the expression of SphK1 (red) in BMSCs (EGFP, green) after 4 weeks of $\mathrm{CCl}_{4}$ treatment. Arrowheads indicate expression of SphK1 in the vascular area and arrows indicate cells positive for both SphK1 and EGFP. DAPI (blue) was used to visualize nuclei. Data are expressed as means \pm SEM. Scale bars: $100 \mu \mathrm{m}(\mathbf{D}) ; 20 \mu \mathrm{m}(\mathbf{E})$.

\section{TGF- $\beta 1$-Induced Differentiation of BMSCs Is} Dependent on SphK1

Having identified the ability of TGF- $\beta 1$ to regulate SphK1 expression in BMSCs, we next evaluated whether the
TGF- $\beta 1$-stimulated BMSC differentiation involves the activation of SphK1. First, we confirmed that TGF- $\beta 1$ treatment induced a significant increase of $\alpha$-SMA, Col $\alpha 1(\mathrm{I})$, and Col $\alpha 1$ (III), with a maximal response at 24 hours (see Supplemental Figure S3 at http://ajp.amjpathol.org). We
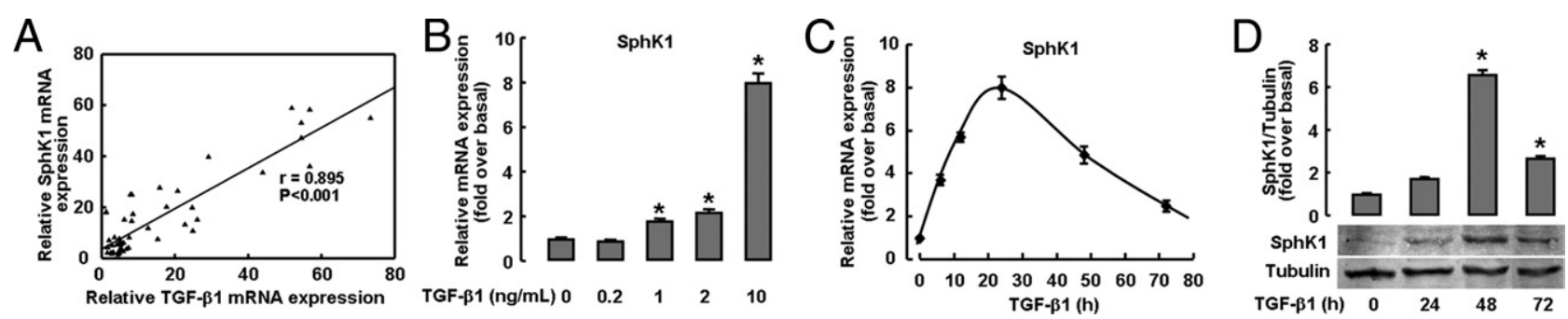

Figure 3. TGF- $\beta 1$ stimulates SphK1 mRNA and protein expression in BMSCs. A: Correlation between SphK1 and TGF- $\beta 1$ mRNA in liver tissue. B: SphK1 mRNA expression in BMSCs treated with five concentrations of TGF- $\beta 1$ ( 0 to $10 \mathrm{ng} / \mathrm{mL})$ for 24 hours. C: SphK1 mRNA expression in BMSCs treated with 10 ng/mL TGF- $\beta 1$ for 0 to 80 hours. D: Cell lysates were prepared and subjected to Western blot analysis. The intensity of each band with SphK1 antibody was quantified and normalized to that with anti- $\beta$-tubulin antibody. All results were confirmed in three independent experiments. Data are expressed as means \pm SEM. ${ }^{*} P<0.05$ versus untreated control cells. 

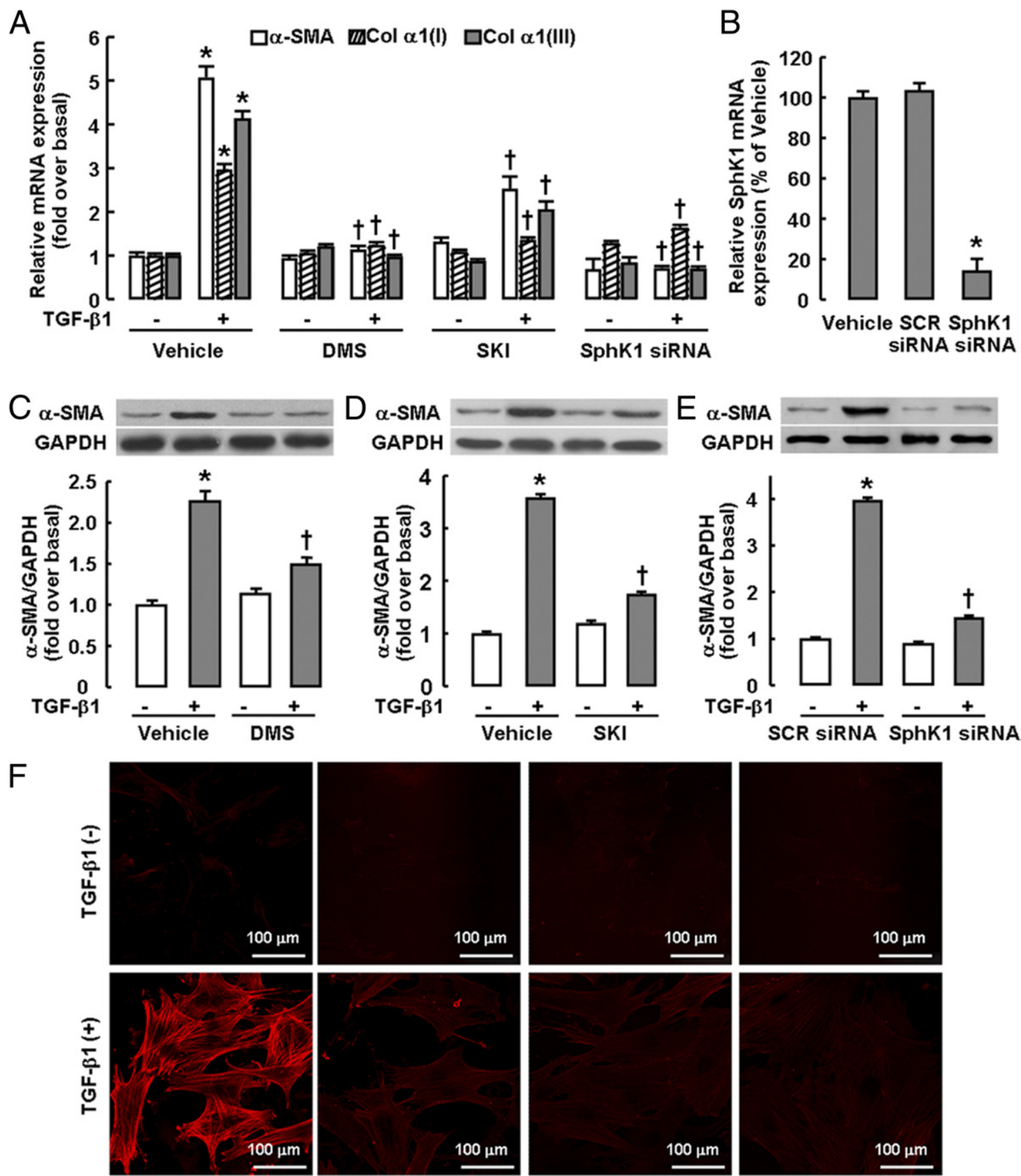

Figure 4. SphK1 is involved in TGF- $\beta 1$-induced differentiation of BMSCs. BMSCs were pretreated or not for 1 hour with $5 \mu \mathrm{mol} / \mathrm{L}$ DMS or $10 \mu \mathrm{mol} / \mathrm{L}$ SKI or were transfected with SphK1 siRNA; 24 hours of TGF- $\beta 1$ treatment followed. A: mRNA expression of $\alpha$-SMA, Col $\alpha 1$ (I), and Col $\alpha 1$ (III) in response to TGF- $\beta 1$ in the presence of DMS, SKI, or SphK1 siRNA. B: Cells were transfected with SCR siRNA or SphK1 for 48 hours. SphK1 mRNA was then evaluated by real-time RT-PCR C-E: $\alpha$-SMA protein expression in response to TGF- $\beta 1$ in the presence of DMS (C), SKI (D), and SphK1 siRNA (E). F: Immunofluorescence analysis of $\alpha$-SMA (red) in BMSCs without $(-)$ or with $(+)$ TGF- $\beta 1$ treatment. All results were confirmed in three independent experiments. Data are expressed as means \pm SEM. ${ }^{*}<$ 0.05 versus untreated control cells; ${ }^{\dagger} P<0.05$ versus TGF- $\beta 1$-treated cells alone. Scale bar $=100 \mu \mathrm{m}$.

used two different pharmacological inhibitors of SphK, DMS and SKI. Enhanced mRNA expression of $\alpha$-SMA, Col $\alpha 1(\mathrm{I})$, and Col $\alpha 1$ (III) induced by TGF- $\beta 1$ was blunted by preincubation with $5 \mu \mathrm{mol} / \mathrm{L}$ DMS or $10 \mu \mathrm{mol} / \mathrm{L}$ SKI for 1 hour before TGF- $\beta 1$ stimulation (Figure 4A). Neither SphK inhibitor alone had any effect on cellular viability (data not shown) or the expression of $\alpha$-SMA, Col $\alpha 1(\mathrm{I})$, and Col $\alpha 1$ (III) (Figure 4A). To further assess the involve- ment of SphK1 in the biological response evoked by TGF- $\beta 1$ in BMSCs, we used siRNA technology to knock down SphK1. First, we confirmed that SphK1 siRNA down-regulated SphK1 mRNA expression, by 86\% (Figure $4 \mathrm{~B})$. In accord with the results for SphK inhibitors, TGF- $\beta 1$-induced $\alpha$-SMA, Col $\alpha 1$ (I), and Col $\alpha 1$ (III) mRNA expression was significantly reduced in SphK1-knockdown cells, whereas scrambled siRNA had no effect 

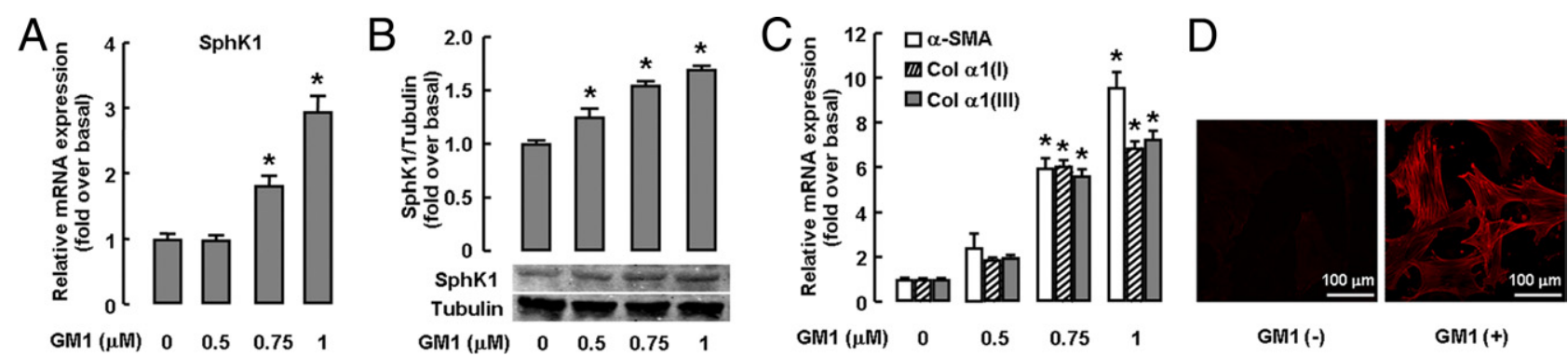

Figure 5. GM1 induces BMSC differentiation. A: SphK1 mRNA expression in BMSCs treated with four concentrations of GM1 ( 0 to $1 \mu$ mol/L) for 24 hours. B: SphK1 and tubulin protein expression by Western blot in BMSCs treated with the four concentrations of GM1. C: mRNA expression of $\alpha$-SMA, Col $\alpha 1$ (I), and Col $\alpha 1$ (III) in BMSCs treated with the four concentrations of GM1 for 24 hours. D: Immunofluorescence analysis of $\alpha$-SMA (red) in BMSCs. All results were confirmed in three independent experiments. Data are expressed as means \pm SEM. ${ }^{*} P<0.05$ versus untreated control cells. Scale bar $=100 \mu \mathrm{m}$.

(Figure 4A). In accord, $\alpha$-SMA protein expression was down-regulated by DMS (Figure 4C), SKI treatment (Figure 4D), and SphK1 siRNA transfection (Figure 4E). These results provide further support for the key role of SphK1 in BMSC differentiation brought about by TGF- $\beta 1$ and strongly suggest that SphK1 contributes to TGF- $\beta 1-$ induced differentiation of BMSCs to myofibroblasts.

To further assess the involvement of SphK1 in BMSC differentiation, we performed immunofluorescent staining for $\alpha$-SMA to reveal morphological changes in BMSCs. Under normal conditions, isolated BMSCs showed very weak expression of $\alpha$-SMA. Treatment of TGF- $\beta 1$ resulted in the appearance of numerous bundles of actin microfilaments and markedly enhanced the expression of $\alpha$-SMA in BMSCs; however, when BMSCs were treated with SphK inhibitors or transfected with SphK1 siRNA, the ability of TGF- $\beta 1$ to enhance $\alpha$-SMA was markedly reduced (Figure 4F).

\section{GM1, a SphK Activator, Exerts a Mimic Effect on BMSC Differentiation as TGF- $\beta 1$}

To further determine whether SphK1 mediates TGF- $\beta 1-$ induced differentiation of BMSCs, we investigated the effects of GM1, a SphK activator, ${ }^{15}$ on BMSC differentiation. As predicted, both SphK1 mRNA (Figure 5A) and SphK1 protein (Figure 5B) levels in BMSCs were elevated after GM1 stimulation. In analogy to TGF- $\beta 1$, GM1 also resulted in a significant increase in $\alpha$-SMA, Col $\alpha 1(\mathrm{I})$, and Col $\alpha 1$ (III) mRNA expression in a dose-dependent manner (Figure 5C). Immunofluorescent staining also showed that GM1 increased the expression of $\alpha$-SMA (Figure 5D). Thus, GM1 may be used to mimic the biological effects of TGF- $\beta 1$ on BMSC differentiation, further confirming that TGF- $\beta 1$ induces differentiation of BMSCs to myofibroblasts via the activation of SphK1.

\section{$S 1 P R_{1}$ and S1PR Are Required for the Differentiation of BMSCs Induced by TGF- $\beta 1$ or GM1}

Activated SphK1 translocates from the cytosol to the plasma membrane, leading to S1P formation, which then activates S1PRs. ${ }^{11}$ We therefore first determined whether TGF- $\beta 1$ or GM1 stimulation resulted in corresponding increases of S1P. Levels of S1P were tested by HPLC in confluent serum-starved cells treated with TGF- $\beta 1$ or GM1 for 24 hours. S1P levels in BMSCs and their supernatants were significantly increased, by approximately 1.9-fold, 1.5-fold, and 3.5-fold after the $10 \mathrm{ng} / \mathrm{mL}$ TGF- $\beta 1$ treatment, the $0.1 \mu \mathrm{mol} / \mathrm{L}$ GM1 treatment, and the 1 $\mu \mathrm{mol} / \mathrm{L}$ GM1 treatment, respectively (Figure 6A).

Next, we examined whether the prodifferentiating action exerted by TGF- $\beta 1$ was S1PR-mediated. The expression of $\alpha$-SMA, Col $\alpha 1(\mathrm{I})$, and Col $\alpha 1$ (III) was evaluated in BMSCs challenged with TGF- $\beta 1$ in the absence or presence of $10 \mu \mathrm{mol} / \mathrm{L}$ JTE-013 (a specific antagonist of $\mathrm{S} \mathrm{PR}_{2}$ ), $1 \mu \mathrm{mol} / \mathrm{L}$ VPC23019 (a specific $\mathrm{S} 1 \mathrm{PR}_{1} / \mathrm{S}_{1 \mathrm{PR}}$ antagonist), or $10 \mu \mathrm{mol} / \mathrm{L}$ W146 (a specific S1PR $\mathrm{S}_{1}$ antagonist) (Figure $6 \mathrm{~B}$ ). The increased content of $\alpha$-SMA, Col $\alpha 1(\mathrm{I})$, and Col $\alpha 1(\mathrm{III})$ after TGF- $\beta 1$ treatment was partially abrogated when $\mathrm{S}_{1} \mathrm{PR}_{1} / \mathrm{S}_{1} \mathrm{PR}_{3}$ was blocked, but was not affected by inhibition of $\mathrm{S}_{1} \mathrm{PR}_{2}$ (Figure $6 \mathrm{~B}$ ), suggesting a role of $\mathrm{S}_{1 \mathrm{PR}} / \mathrm{S}_{1} \mathrm{PR}_{3}$ but not $\mathrm{S} 1 \mathrm{PR}_{2}$ in TGF- $\beta 1-$ induced response. Furthermore, differentiation of BMSCs induced by TGF- $\beta 1$ was partially abrogated when S1PR was blocked by its specific antagonist, W146 (Figure 6B). Next, we used an agonist of S1PR 1 (SEW2871) to further investigate the effect of $\mathrm{S}_{1 \mathrm{PR}}$ on BMSC differentiation. This $\mathrm{S} 1 \mathrm{PR}_{1}$ agonist also increased the expression of $\alpha$-SMA, Col $\alpha 1(\mathrm{I})$, and Col $\alpha 1(\mathrm{III})$ (Figure 6C).

To further test this hypothesis, individual S1PRs were knocked down by specific siRNAs. First, we confirmed that $\mathrm{S}_{1 \mathrm{PR}}, \mathrm{S}_{1} \mathrm{PR}_{2}$, or $\mathrm{S} 1 \mathrm{PR}_{3}$ siRNA down-regulated each mRNA expression (by $87 \%, 86 \%$, and $75 \%$, respectively). $\mathrm{S}_{1 P R_{1}}$ or $\mathrm{S}_{1 P R_{3}}$ SiRNA strongly attenuated the enhancement of $\alpha$-SMA and Col $\alpha 1$ (I) mRNA expression elicited by TGF- $\beta 1$ and abrogated the increase of Col $\alpha 1$ (III) mRNA expression. Conversely, the down-regulation of $\mathrm{S} \mathrm{PR}_{2}$ by specific siRNA did not alter the prodifferentiating effect of the cytokine (Figure 6D). Altogether, these data suggest that $\mathrm{S}_{1 \mathrm{PR}}$ and $\mathrm{S}_{1} \mathrm{PR}_{3}$ are required for the differentiation of BMSCs induced by TGF- $\beta 1$.

To further investigate the role of S1PRs in BMSC differentiation, BMSCs were preincubated with inhibitors or transfected with specific siRNAs of S1PRs, to test for the responsiveness to GM1. Consistent with the findings for TGF- $\beta 1$ treatment, knockdown of $\mathrm{S}_{1 \mathrm{PR}}$ or $\mathrm{S}_{1} \mathrm{PR}_{3}$ blunted the increase of $\alpha$-SMA, Col $\alpha 1(\mathrm{I})$, and Col $\alpha 1$ (III) mRNA expression induced by GM1, whereas knockdown of $\mathrm{S}_{\mathrm{PR}}$, had no effect (Figure 6E). These results indicate that $\mathrm{S}_{1 P R_{1}}$ and $\mathrm{S}_{1} \mathrm{PR}_{3}$ are essential for $\mathrm{GM} 1$-induced 

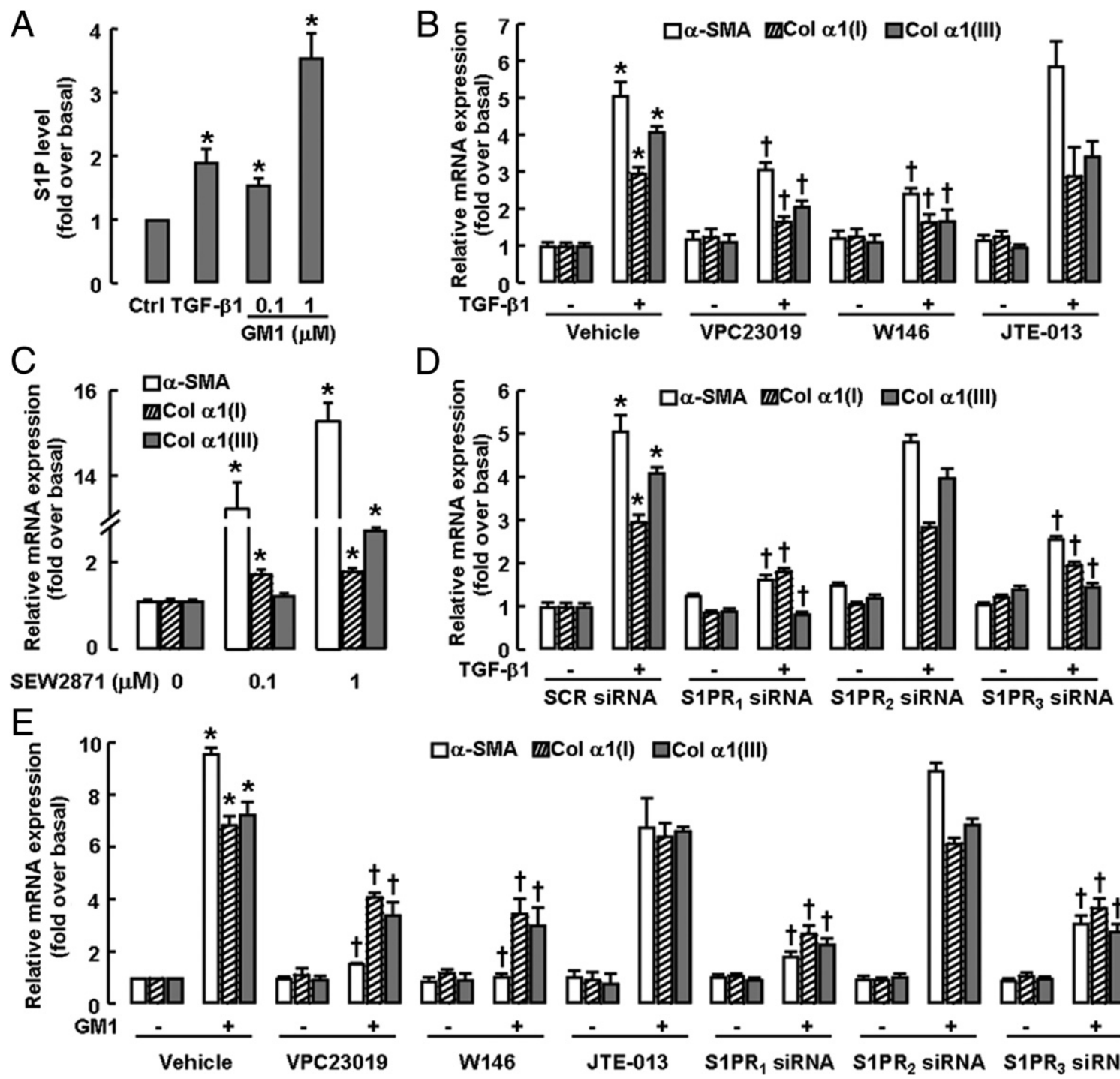

$\square \alpha-S M A$ mCol $\alpha 1$ (I) $\square \operatorname{Col} \alpha 1$ (III)

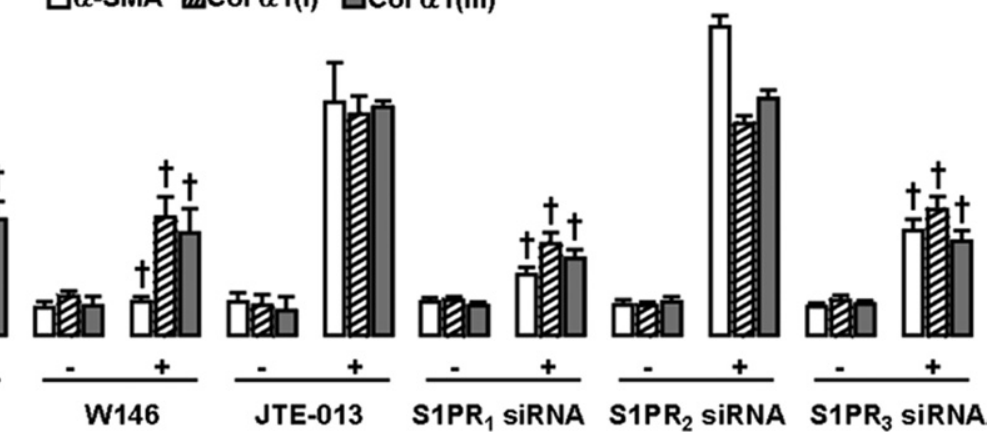

Figure 6. Role of S1PRs in TGF- $\beta 1$-induced or GM1-induced differentiation of BMSCs. A: S1P levels in BMSCs after treatment with TGF- $\beta 1$ or GM1. B: BMSCs were treated without $(-)$ or with (+) $1 \mu \mathrm{mol} / \mathrm{L}$ VPC23019, $1 \mu \mathrm{mol} / \mathrm{L}$ W146, or $10 \mu \mathrm{mol} / \mathrm{L}$ JTE- 013 for 1 hour before TGF- $\beta 1 \mathrm{challenge} \mathrm{(10} \mathrm{ng/mL)} \mathrm{for} 24 \mathrm{hours}$, mRNA expression of $\alpha$-SMA, Col $\alpha 1(\mathrm{I})$, and Col $\alpha 1(\mathrm{III})$ was analyzed by real-time RT-PCR. C: The mRNA expression of $\alpha$-SMA, Col $\alpha 1(\mathrm{I})$, and Col $\alpha 1(\mathrm{III})$ in response to SEW2871. D: BMSCs, transfected with SCR or S1PR siRNAs and incubated in the absence $(-)$ or presence $(+)$ of $10 \mathrm{ng} / \mathrm{mL}$ TGF- $\beta 1$ for the last $24 \mathrm{hours}$ of transfection, were evaluated for mRNA expression of $\alpha$-SMA, Col $\alpha 1$ (I), and Col $\alpha 1$ (III). E: Effects of S1PR inhibitors or specific siRNAs on the mRNA expression of $\alpha$-SMA, Col $\alpha 1(\mathrm{I})$, and Col $\alpha 1$ (III) in response to GM1. All results were confirmed in three independent experiments. Data are expressed as means \pm SEM. ${ }^{*} P<0.05$ versus untreated control cells; ${ }^{\dagger} P<0.05$ versus TGF- $\beta 1$-treated or GM1-treated cells alone.

BMSC differentiation, further supporting the critical role of S1PRs in TGF- $\beta 1$-induced MSC differentiation.

\section{TGF- $\beta 1$ or GM1, But Not Exogenous S1P, Modifies S1PR Expression Pattern}

To gain further insight into the mechanism by which TGF- $\beta 1$ exploits the SphK/S1P/S1PR axis to exert its prodifferentiating effect in BMSCs, we examined whether cell treatment with the cytokine affected S1PR expression pattern. Real-time RT-PCR analysis showed that incubation of BMSCs for 24 hours in the presence of TGF- $\beta 1$ apparently up-regulated the expression of $\mathrm{S}_{1} \mathrm{PR}_{1}$ and $\mathrm{S}_{1 P R}$ (Figure 7A). Similar results were obtained after GM1 stimulation (Figure 7B). Exogenous S1P, however, did not affect S1PR expression levels (Figure 7C). Given that TGF- $\beta 1$ or GM1 could induce BMSC differentiation, whereas exogenous S1P had no direct effect on it, these findings further confirm that up-regulation of $\mathrm{S}_{1} \mathrm{PR}_{1}$ and $\mathrm{S} 1 P R_{3}$ on TGF- $\beta 1$ or GM1 challenge is essential for the differentiation of BMSCs to myofibroblasts.

\section{Blockage of SphK Attenuates $\mathrm{CCl}_{4}$-Induced Liver Fibrosis}

Finally, we analyzed the effects of the SphK inhibitor SKI on the underlying liver fibrosis process. Hepatic collagen deposition was evaluated by morphometric analysis with Sirius Red staining and was quantified by digital image analysis. Collagen deposition was markedly attenuated after SKI administration (Figure 8, A and C). Moreover, H\&E-stained sections showed a significant decrease in 

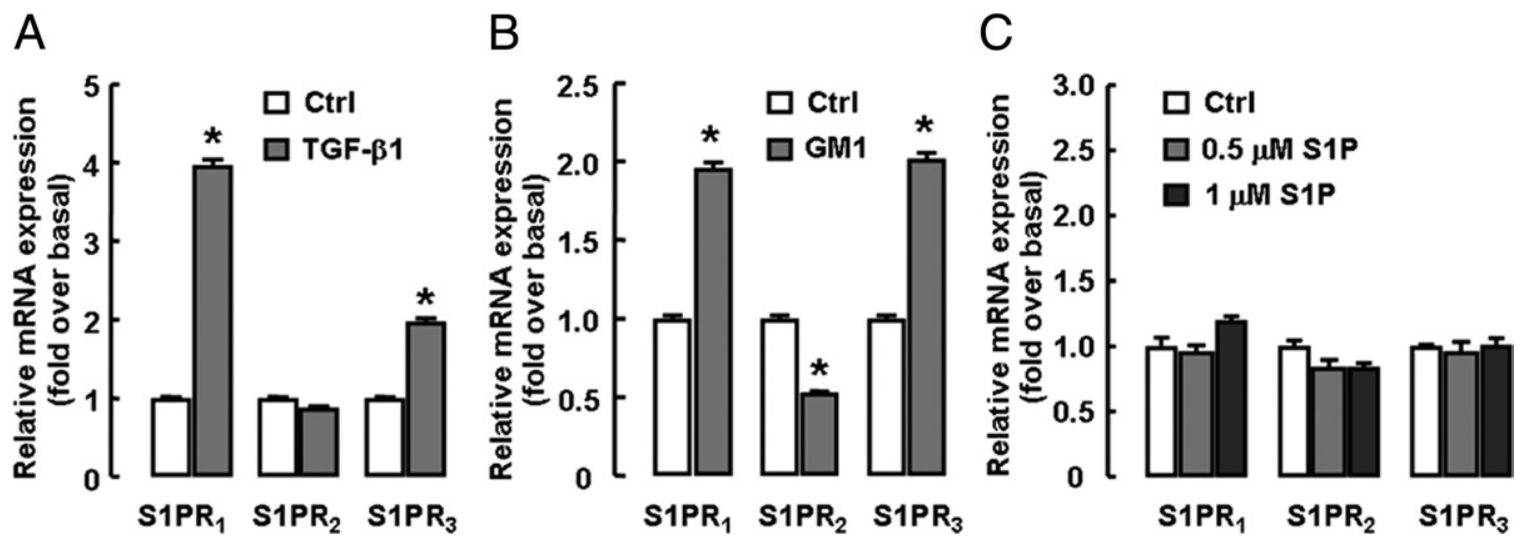

Figure 7. TGF- $\beta 1$ or GM1, but not exogenous S1P, modifies S1PR expression pattern. mRNA expression of S1PRs after TGF- $\beta 1$ (A), GM1 (B), or exogenous S1P (C) stimulation for 24 hours was analyzed by real-time RT-PCR. * $P<0.05$ versus control.

liver injury after SKI administration in $\mathrm{CCl}_{4}$-treated mice (Figure 8B). We also examined the effect of SKI on the fibrosis markers $\alpha$-SMA, Col $\alpha 1(\mathrm{I})$, and Col $\alpha 1(\mathrm{III})$ in $\mathrm{CCl}_{4^{-}}$ induced mouse liver fibrosis. After 4 weeks of administration of $\mathrm{CCl}_{4}$, mRNA expressions of $\alpha$-SMA, Col $\alpha 1(\mathrm{I})$, and $\mathrm{Col} \alpha 1$ (III) in liver tissue were markedly up-regulated; however, SKI administration resulted in a significant drop in mRNA expression of $\alpha$-SMA (Figure 8D), Col $\alpha 1$ (I) (Figure $8 \mathrm{E}$ ), and Col $\alpha 1(\mathrm{III})$ (Figure $8 \mathrm{~F}$ ), compared with control. These results demonstrate that blockage of SphK attenuates $\mathrm{CCl}_{4}$-induced liver fibrosis.

\section{Discussion}

Understanding the regulatory mechanisms at the molecular level underlying BMSC differentiation is a prerequi- site for optimizing mesenchymal stem cell-based clinical applications. Here, we have described a novel signaling pathway, triggered by TGF- $\beta 1$ in BMSCs via modulation of SphK1 and $\mathrm{S}_{1 P R_{1 / 3}}$, that is critically implicated in the differentiation of BMSCs to myofibroblasts.

A key finding of the present study is that SphK1 is implicated in the prodifferentiating action of TGF- $\beta 1$ on BMSCs. First, we examined the in vivo expression of SphK1 by immunofluorescence analysis in $\mathrm{CCl}_{4}$-induced liver fibrosis models and found that SphK1 is expressed in BMSCs in the damaged liver. Together with the drastic increase in SphK1 mRNA level after liver injury, these results suggest that SphK1 is highly involved in the differentiation of BMSCs to myofibroblasts. We demonstrated for the first time in vitro that TGF- $\beta 1$-directed regulation of SphK1 is involved in the up-regulation of
A

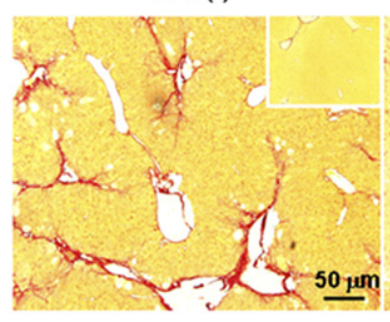

C

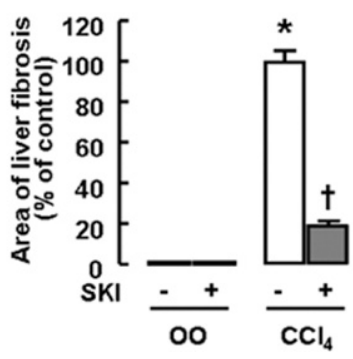

SKI (+)
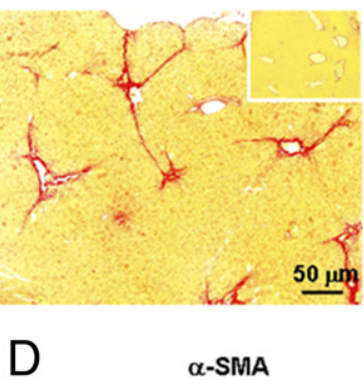

B

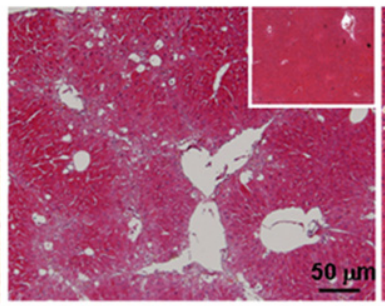

$\mathrm{E}$

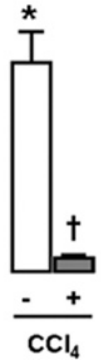

Col $\alpha 1(\mathrm{I})$

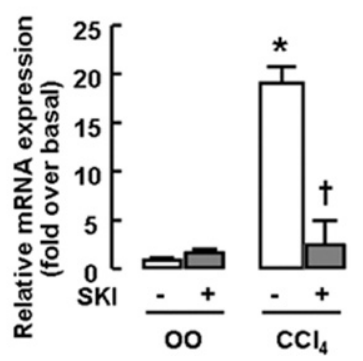

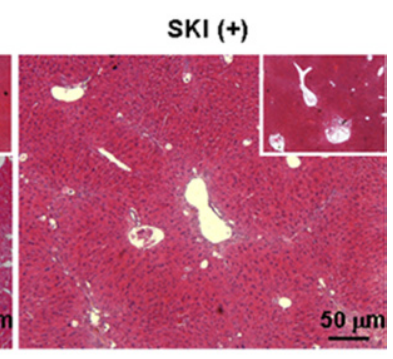

$\mathrm{F}$

Col $\alpha 1$ (III)

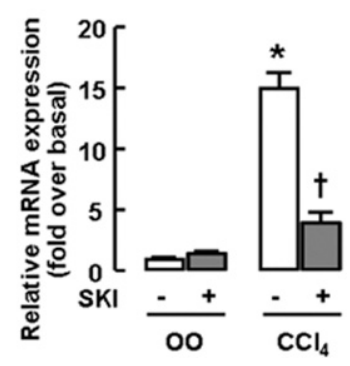

Figure 8. The effect of SphK blockage on $\mathrm{CCl}_{-}$-induced liver fibrosis in mice. A: Representative images of Sirius Red staining in the absence $(-)$or presence $(+)$ of the SphK inhibitor SKI after $\mathrm{CCl}_{4}$ administration. Inset: Sirius Red staining for OO-treated liver. B: Representative H\&E-stained liver sections in the absence ( - ) or presence $(+)$ of SKI after $\mathrm{CCl}_{4}$ administration. Inset: H\&E staining for OO-treated livers. C: For quantitative analysis of liver fibrosis, 15 randomly selected fields were quantitated for each mouse using the Leica Qwin V3 software. Relative hepatic levels of $\alpha$-SMA (D), Col $\alpha 1$ (I) (E), and Col $\alpha 1$ (III) (F) were determined by real-time RT-PCR. Data are expressed as means \pm SEM. ${ }^{*} P<0.05$ versus control. ${ }^{\dagger} P<0.05$ versus $\mathrm{CCl}_{4}$-treated alone. Scale bar $=50 \mu \mathrm{m}(\mathbf{m a i n}$ images and insets). 
myofibroblast marker proteins during BMSC differentiation. When TGF- $\beta 1$-stimulated increase in SphK 1 expression is inhibited with siRNA or a SphK inhibitor, the mRNA expression of $\alpha$-SMA, Col $\alpha 1$ (I), and Col $\alpha 1$ (III) and the protein expression of $\alpha$-SMA stimulated by TGF- $\beta 1$ are abrogated. These results are in agreement with recent reports that highlight a pivotal role of TGF- $\beta 1$-directed SphK1 up-regulation in mediating the prodifferentiating action in different types of fibroblasts and myocytes, ${ }^{25-28}$ and suggests that endogenous S1P production is necessary for BMSC differentiation induced by TGF- $\beta 1$.

Importantly, to evaluate the role of SphK1 in BMSC differentiation in vivo, we performed an animal experiment by administration of a SphK inhibitor, SKI. We characterized the EGFP-positive cells by staining for $\alpha$-SMA, with confocal analysis, and determined the proportion of BMSC-derived myofibroblasts. Our results show that SKI significantly blocks BMSC differentiation to myofibroblasts during liver injury, because the proportion of BMSC-derived myofibroblasts decreased markedly, compared with that in the liver without SKI treatment, thus attenuating the extent of liver fibrosis. A recent report indicated that bone marrow-derived cells do not contribute significantly to liver fibrosis. ${ }^{34}$ In the present study, however, we do observe BMSC-derived myofibroblasts in the injured liver. In addition, reports from several experimental and human studies indicate that bone marrowderived cells can differentiate to hepatic stellate cells, myofibroblasts, and fibrocytes, and may participate in liver fibrosis. . $^{8,35}$

Although the exact origin of myofibroblasts in liver injury and fibrosis is yet to be determined, it is often presumed that they derive from local activation of residential fibroblasts, hepatic stellate cells, or epithelial-mesenchymal transition. Consistent with previous reports, we confirm that BMSCs contribute to liver fibrosis during $\mathrm{CCl}_{4-}$ induced liver fibrosis. Thus, the profibrotic potential of BMSCs should not be underestimated, in particular when BSMCs are used as therapy for fibrosis or cirrhosis.

GM1 is a ganglioside that activates sphingosine kinase to increase intracellular levels of S1P. ${ }^{36}$ We used GM1 as a tool to indirectly confirm the important role of SphK1 and S1PRs in BMSC differentiation induced by TGF- $\beta 1$. Our data suggest that GM1 is an important, previously unrecognized mediator of liver fibrosis through both direct and indirect effects on BMSC differentiation, and that GM1 markedly increases mRNA and protein expression of SphK1 and stimulates endogenous S1P production in BMSCs. Moreover, like TGF- $\beta 1$, GM1 modulates the expression of S1PRs and induces BMSC differentiation via up-regulation of $\mathrm{S}_{\mathrm{PR}}$ and $\mathrm{S}_{1} \mathrm{PR}_{3}$, which is in accord with a report that, in mouse cardiomyocytes, S1P generated by GM1 treatment must be exported from the cell and couple with its cognate receptor to exert the biological effects. ${ }^{37}$ These data support the hypothesis that TGF- $\beta 1$ stimulates SphK1 expression, leading to production of endogenous S1P, which is then released and acts on $\mathrm{S}_{1} \mathrm{PR}_{1}$ and $\mathrm{S}_{1} \mathrm{PR}_{3}$ to exert final prodifferentiating effects. Although the reason why GM1 increased S1PR and $\mathrm{S}_{1} \mathrm{PR}_{3}$ expression but decreased $\mathrm{S}_{\mathrm{PR}}$ expression is not yet clear, GM1 could be used as a positive control to further demonstrate the role of SphK1. To our knowledge, this is the first time that GM1 has been shown to mimic TGF- $\beta 1$ signaling and to have a direct role in BMSC differentiation, suggesting crosstalk between TGF- $\beta 1$ and S1P signaling pathways in BMSCs.

Another novel finding of the present study is that upregulation of $\mathrm{S}_{\mathrm{PR}}$ and $\mathrm{S}_{1} \mathrm{PR}_{3}$ is essential for the differentiation of BMSCs to myofibroblasts. We found that exogenous S1P does not directly induce BMSC differentiation. In contrast, endogenous S1P, generated by TGF- $\beta 1$ or GM1, modulates the expression of S1PRs and induces BMSC differentiation. A robust prodifferentiating effect of S1P has been identified in other cellular contexts, including fibroblasts, myoblasts, and retinal pigmented epithelial cells. ${ }^{27,38-41} \mathrm{~A}$ possible explanation for this discrepancy is the different effects of S1P on its receptors. In the present study, exogenous S1P treatment did not affect the expression of S1PRs; whereas endogenous S1P modified S1PR expression pattern by up-regulation of $\mathrm{S} 1 \mathrm{PR}$, and $\mathrm{S}_{1} \mathrm{PR}_{3}$, which were shown to be involved in the final prodifferentiating effects. Further studies are needed to elucidate the exact mechanism of the different effects of exogenous versus endogenous S1P on S1PRs.

The S1PR subtypes are expressed in distinct combinations in different cell types to produce an appropriate biological action. The functional response of each cell to S1P varies, depending on the S1PR repertoire. We previously showed that $\mathrm{S} 1 \mathrm{PR}_{1}, \mathrm{~S} 1 \mathrm{PR}_{2}$, and $\mathrm{S} 1 \mathrm{PR}_{3}$ are abundant in mouse BMSCs. ${ }^{9}$ In the present study, we analyzed the early intracellular signaling events of BMSC differentiation triggered by TGF- $\beta 1$. Our results show that $\mathrm{S}_{1 P R_{1}}$ and $\mathrm{S}_{1 \mathrm{PR}}$ are up-regulated after TGF- $\beta 1$ or GM1 stimulation and that their inhibition by selective antagonists or knockdown by specific siRNAs blunts the increase of $\alpha$-SMA, Col $\alpha 1(\mathrm{I})$, and Col $\alpha 1(\mathrm{III})$ induced by TGF- $\beta 1$ or GM1, suggesting the critical role of S1PR 1 and $\mathrm{S}_{\mathrm{PR}}$ in the regulation of BMSC differentiation. In addition, we found that the S1PR 1 agonist SEW2871 can mimic the effects of TGF- $\beta 1$ by increasing the expression of $\alpha$-SMA, Col $\alpha 1(\mathrm{I})$, and Col $\alpha 1(\mathrm{III})$. These results are in accord with several published reports, which together support a key role of S1PRs in transmitting the prodifferentiating action of TGF- $\beta 1$. For example, $\mathrm{S}_{\mathrm{PR}}$ and $\mathrm{S}_{\mathrm{PR}} \mathrm{R}_{3}$ were previously identified as downstream of TGF- $\beta 1$ regulation of $\alpha$-SMA expression in lung fibroblasts. ${ }^{26}$ Furthermore, knockdown of $\mathrm{S} 1 \mathrm{PR}_{2}$ using siRNA completely suppressed TGF- $\beta 1$-stimulated collagen production and differentiation of cardiac fibroblasts to myofibroblasts. ${ }^{27}$ More recently, Cencetti et al ${ }^{28}$ reported that $\mathrm{S}_{\mathrm{PR}}$ plays a key role in the TGF- $\beta 1$-induced differentiation of myocytes to myofibroblasts. Taken together, our findings suggest that up-regulation of $\mathrm{S}_{1} \mathrm{PR}_{1}$ and $\mathrm{S}_{\mathrm{PR}}$ by TGF- $\beta 1$ or GM1 is required for the differentiation of BMSCs to myofibroblasts. It is possible that TGF- $\beta 1$ regulates the differentiation of BMSCs to myofibroblasts by remodeling expression of S1PRs.

The mechanism by which TGF- $\beta 1$-related molecules elicit their multiple biological effects is quite complex and has not yet been fully elucidated. Although TGF- $\beta 1$ is known to induce these different responses through the same receptor complex and Smad proteins, over the last 
few years it has been shown that the cytokine can activate several non-Smad signaling pathways in a cell-typespecific fashion. ${ }^{42-46}$ The Rho/Rho kinase pathway is one of the important pathways for TGF- $\beta 1$-induced response in addition to Smad signaling. This pathway is known to be involved in the fibrotic process that affects multiple different tissues ${ }^{47-49}$ and is necessary for mature myofibroblasts. ${ }^{26-28}$ For example, Rho/Rho kinase was involved in $\mathrm{S}_{1} \mathrm{PR}_{3}$-dependent up-regulation of fibrosis marker expression brought about by TGF- $\beta 1$ in the differentiation of myocytes to myofibroblasts. ${ }^{28}$ Furthermore, Rho kinase was also implicated in the mechanism by which SphK1 regulates differentiation of lung fibroblasts mediated by TGF- $\beta 1{ }^{26}$ Consistent with these findings, Gellings Lowe et a ${ }^{27}$ demonstrated that S1P-stimulated myofibroblast transformation and collagen production are dependent on activation of Rho kinase. In addition, connective tissue growth factor (CTGF) was also shown to be a downstream mediator of TGF- $\beta 1,50$ and IGFBP3 has been implicated in S1P pathway. ${ }^{51}$ However, whether Rho signals or other signaling pathways are implicated in BMSC differentiation remains to be investigated. Here, we have focused on the relationship between the SphK/S1P/S1PR axis and TGF- $\beta 1$ during BMSC differentiation to myofibroblasts. Further insight into crosstalk between the Smad, Rho, CTGF, and/or IGF-BP3 pathways and the SphK pathway is important for understanding BMSC differentiation induced by TGF- $\beta 1$.

In conclusion, with this study we have identified the unique ability of TGF- $\beta 1$ to exploit S1P signaling to differentiate BMSCs to myofibroblasts by simultaneously affecting SphK1 and S1PR expression pattern. We thus provide new clues to the molecular mechanisms underlying the differentiation of BMSCs elicited by the cytokine, which may open new perspectives for pharmacological treatment of liver fibrosis.

\section{Acknowledgments}

We thank Shi Yue and Xihong Liu for providing some of the mouse tissues.

\section{References}

1. Caplan Al: Mesenchymal stem cells. J Orthop Res 1991, 9:641-650

2. Pittenger MF, Mackay AM, Beck SC, Jaiswal RK, Douglas R, Mosca JD, Moorman MA, Simonetti DW, Craig S, Marshak DR: Multilineage potential of adult human mesenchymal stem cells. Science 1999, 284:143-147

3. Watabe T, Miyazono K: Roles of TGF-beta family signaling in stem cell renewal and differentiation. Cell Res 2009, 19:103-115

4. Friedman SL: Mechanisms of hepatic fibrogenesis. Gastroenterology 2008, 134:1655-1669

5. Desmoulière A, Darby IA, Gabbiani G: Normal and pathologic soft tissue remodeling: role of the myofibroblast, with special emphasis on liver and kidney fibrosis. Lab Invest 2003, 83:1689-1707

6. Forbes SJ, Russo FP, Rey V, Burra P, Rugge M, Wright NA, Alison MR: A significant proportion of myofibroblasts are of bone marrow origin in human liver fibrosis. Gastroenterology 2004, 126:955-963

7. Kallis YN, Alison MR, Forbes SJ: Bone marrow stem cells and liver disease. Gut 2007, 56:716-724

8. Russo FP, Alison MR, Bigger BW, Amofah E, Florou A, Amin F, Bou-Gharios G, Jeffery R, Iredale JP, Forbes SJ: The bone marrow functionally contributes to liver fibrosis. Gastroenterology 2006, 130:1807-1821

9. Li C, Kong Y, Wang H, Wang S, Yu H, Liu X, Yang L, Jiang X, Li L, Li L: Homing of bone marrow mesenchymal stem cells mediated by sphingosine 1-phosphate contributes to liver fibrosis [Erratum appeared in J Hepatol 2009, 51:973]. J Hepatol 2009, 50:1174-1183

10. Watterson KR, Lanning DA, Diegelmann RF, Spiegel S: Regulation of fibroblast functions by lysophospholipid mediators: potential roles in wound healing. Wound Repair Regen 2007, 15:607-616

11. Maceyka M, Sankala H, Hait NC, Le Stunff H, Liu H, Toman R, Collier C, Zhang M, Satin LS, Merrill AJ, Milstien S, Spiegel S: SphK1 and SphK2, sphingosine kinase isoenzymes with opposing functions in sphingolipid metabolism. J Biol Chem 2005, 280:37118-37129

12. Taha TA, Hannun YA, Obeid LM: Sphingosine kinase: biochemical and cellular regulation and role in disease. J Biochem Mol Biol 2006 , $39: 113-131$

13. Donati C, Cencetti F, Nincheri P, Bernacchioni C, Brunelli S, Clement E, Cossu G, Bruni P: Sphingosine 1-phosphate mediates proliferation and survival of mesoangioblasts. Stem Cells 2007, 25:1713-1719

14. Meacci E, Nuti F, Donati C, Cencetti F, Farnararo M, Bruni P: Sphingosine kinase activity is required for myogenic differentiation of C2C12 myoblasts. J Cell Physiol 2008, 214:210-220

15. Karliner JS, Honbo N, Summers K, Gray MO, Goetzl EJ: The lysophospholipids sphingosine-1-phosphate and lysophosphatidic acid enhance survival during hypoxia in neonatal rat cardiac myocytes. $J$ Mol Cell Cardiol 2001, 33:1713-1717

16. Rosen H, Goetzl EJ: Sphingosine 1-phosphate and its receptors: an autocrine and paracrine network. Nat Rev Immunol 2005, 5:560-570

17. Alvarez SE, Milstien S, Spiegel S: Autocrine and paracrine roles of sphingosine-1-phosphate. Trends Endocrinol Metab 2007, 18:300307

18. Hannun YA, Obeid LM: Principles of bioactive lipid signalling: lessons from sphingolipids. Nat Rev Mol Cell Biol 2008, 9:139-150

19. Massagué J: TGF-beta signal transduction. Annu Rev Biochem 1998 , 67:753-791

20. Blobe GC, Schiemann WP, Lodish HF: Role of transforming growth factor beta in human disease. N Engl J Med 2000, 342:1350-1358

21. Jeon ES, Moon HJ, Lee MJ, Song HY, Kim YM, Bae YC, Jung JS, Kim $\mathrm{JH}$ : Sphingosylphosphorylcholine induces differentiation of human mesenchymal stem cells into smooth-muscle-like cells through a TGF-beta-dependent mechanism. J Cell Sci 2006, 119:4994-5005

22. Song HY, Kim MY, Kim KH, Lee IH, Shin SH, Lee JS, Kim JH: Synovial fluid of patients with rheumatoid arthritis induces alpha-smooth muscle actin in human adipose tissue-derived mesenchymal stem cells through a TGF-beta1-dependent mechanism. Exp Mol Med 2010 42:565-573

23. Miller AV, Alvarez SE, Spiegel S, Lebman DA: Sphingosine kinases and sphingosine-1-phosphate are critical for transforming growth factor beta-induced extracellular signal-regulated kinase 1 and 2 activation and promotion of migration and invasion of esophageal cancer cells. Mol Cell Biol 2008, 28:4142-4151

24. Donati C, Cencetti F, De Palma C, Rapizzi E, Brunelli S, Cossu G, Clementi E, Bruni P: TGFbeta protects mesoangioblasts from apoptosis via sphingosine kinase-1 regulation. Cell Signal 2009, 21:228236

25. Yamanaka M, Shegogue D, Pei H, Bu S, Bielawska A, Bielawski J, Pettus B, Hannun YA, Obeid L, Trojanowska M: Sphingosine kinase 1 (SPHK1) is induced by transforming growth factor-beta and mediates TIMP-1 up-regulation. J Biol Chem 2004, 279:53994-54001

26. Kono $Y$, Nishiuma $T$, Nishimura $Y$, Kotani $Y$, Okada T, Nakamura S, Yokoyama M: Sphingosine kinase 1 regulates differentiation of human and mouse lung fibroblasts mediated by TGF-beta1. Am J Respir Cell Mol Biol 2007, 37:395-404

27. Gellings Lowe N, Swaney JS, Moreno KM, Sabbadini RA: Sphingosine-1-phosphate and sphingosine kinase are critical for transforming growth factor-beta-stimulated collagen production by cardiac fibroblasts. Cardiovasc Res 2009, 82:303-312

28. Cencetti F, Bernacchioni C, Nincheri P, Donati C, Bruni P: Transforming growth factor-beta1 induces transdifferentiation of myoblasts into myofibroblasts via up-regulation of sphingosine kinase-1/S1P3 axis. Mol Biol Cell 2010, 21:1111-1124

29. Li C, Zheng S, You H, Liu X, Lin M, Yang L, Li L: Sphingosine 1-phosphate (S1P)/S1P receptors are involved in human liver fibrosis 
by action on hepatic myofibroblasts motility [Erratum appeared in J Hepatol 2012, 56:749]. J Hepatol 2011, 54:1205-1213

30. Li C, Jiang X, Yang L, Liu X, Yue S, Li L: Involvement of sphingosine 1-phosphate (SIP)/S1P3 signaling in cholestasis-induced liver fibrosis. Am J Pathol 2009, 175:1464-1472

31. Manton KJ, Leong DF, Cool SM, Nurcombe V: Disruption of heparan and chondroitin sulfate signaling enhances mesenchymal stem cellderived osteogenic differentiation via bone morphogenetic protein signaling pathways. Stem Cells 2007, 25:2845-2854

32. Liu X, Yue S, Li C, Yang L, You H, Li L: Essential roles of sphingosine 1-phosphate receptor types 1 and 3 in human hepatic stellate cells motility and activation. J Cell Physiol 2011, 226:2370-2377

33. Venkataraman K, Lee YM, Michaud J, Thangada S, Ai Y, Bonkovsky HL, Parikh NS, Habrukowich C, Hla T: Vascular endothelium as a contributor of plasma sphingosine 1-phosphate. Circ Res 2008, 102:669-676

34. Higashiyama R, Moro T, Nakao S, Mikami K, Fukumitsu H, Ueda $Y$, Ikeda K, Adachi E, Bou-Gharios G, Okazaki I, Inagaki Y: Negligible contribution of bone marrow-derived cells to collagen production during hepatic fibrogenesis in mice. Gastroenterology 2009, 137: 1459-1466.e1

35. Terai $\mathrm{S}$, Ishikawa $\mathrm{T}$, Omori $\mathrm{K}$, Aoyama $\mathrm{K}$, Marumoto $\mathrm{Y}$, Urata $\mathrm{Y}$, Yokoyama Y, Uchida K, Yamasaki T, Fujii Y, Okita K, Sakaida I: Improved liver function in patients with liver cirrhosis after autologous bone marrow cell infusion therapy. Stem Cells 2006, 24:2292-2298

36. Jin ZQ, Zhou HZ, Zhu P, Honbo N, Mochly-Rosen D, Messing RO, Goetzl EJ, Karliner JS, Gray MO: Cardioprotection mediated by sphingosine-1-phosphate and ganglioside GM-1 in wild-type and PKC epsilon knockout mouse hearts. Am J Physiol Heart Circ Physiol 2002, 282: $\mathrm{H} 1970-\mathrm{H} 1977$

37. Tao R, Zhang J, Vessey DA, Honbo N, Karliner JS: Deletion of the sphingosine kinase-1 gene influences cell fate during hypoxia and glucose deprivation in adult mouse cardiomyocytes. Cardiovasc Res 2007, 74:56-63

38. Keller CD, Rivera GP, Tolle M, van der Giet M, Chun J, Radeke HH, Schafer-Korting M, Kleuser B: Immunomodulator FTY720 induces myofibroblast differentiation via the lysophospholipid receptor S1P3 and Smad3 signaling. Am J Pathol 2007, 170:281-292

39. Urata Y, Nishimura Y, Hirase T, Yokoyama M: Sphingosine 1-phosphate induces alpha-smooth muscle actin expression in lung fibroblasts via rho-kinase. Kobe J Med Sci 2005, 51:17-27
40. Swaney JS, Moreno KM, Gentile AM, Sabbadini RA, Stoller GL: Sphingosine-1-phosphate (S1P) is a novel fibrotic mediator in the eye. Exp Eye Res 2008, 87:367-375

41. Donati C, Meacci E, Nuti F, Becciolini L, Farnararo M, Bruni P. Sphingosine 1-phosphate regulates myogenic differentiation: a major role for S1P2 receptor. FASEB J 2005, 19:449-451

42. Javelaud D, Mauviel A: Crosstalk mechanisms between the mitogenactivated protein kinase pathways and Smad signaling downstream of TGF-beta: implications for carcinogenesis. Oncogene 2005, 24 : 5742-5750

43. Bhowmick NA, Zent R, Ghiassi M, McDonnell M, Moses HL: Integrin beta 1 signaling is necessary for transforming growth factor-beta activation of p38MAPK and epithelial plasticity. J Biol Chem 2001, 276:46707-46713

44. Zavadil J, Bitzer M, Liang D, Yang YC, Massimi A, Kneitz S, Piek E, Bottinger EP: Genetic programs of epithelial cell plasticity directed by transforming growth factor-beta. Proc Natl Acad Sci USA 2001, 98 : 6686-6691

45. Bakin AV, Tomlinson AK, Bhowmick NA, Moses HL, Arteaga CL: Phosphatidylinositol 3-kinase function is required for transforming growth factor beta-mediated epithelial to mesenchymal transition and cell migration. J Biol Chem 2000, 275:36803-36810

46. Hartsough MT, Mulder KM: Transforming growth factor beta activation of p44mapk in proliferating cultures of epithelial cells. J Biol Chem 1995, 270:7117-7124

47. Haudek SB, Gupta D, Dewald O, Schwartz RJ, Wei L, Trial J, Entman ML: Rho kinase- 1 mediates cardiac fibrosis by regulating fibroblast precursor cell differentiation. Cardiovasc Res 2009, 83:511-518

48. Dolman ME, Fretz MM, Segers GJ, Lacombe M, Prakash J, Storm G Hennink WE, Kok RJ: Renal targeting of kinase inhibitors. Int J Pharm 2008, 364:249-257

49. Soon RJ Jr, Yee HJ Jr: Stellate cell contraction: role, regulation, and potential therapeutic target. Clin Liver Dis 2008, 12:791-803, viii

50. Michelle M, Andrew L, Judith A, George F, Alison H: CTGF Expression is induced by TGF- $\beta$ in cardiac fibroblasts and cardiac myocytes: a potential role in heart fibrosis. J Mol Cell Cardiol 2000, 32:1805-1819

51. Granata R, Trovato L, Lupia E, Sala G, Settanni F, Camussi G, Ghidoni R, Ghigo E: Insulin-like growth factor binding protein-3 induces angiogenesis through IGF-1- and SphK1-dependent mechanisms. J Thromb Haemost 2007, 5:835-845 